\title{
Diderot e o romantismo na política
}

\author{
Ana Portich - Unesp/ Marília
}

As teorias de Diderot sobre a origem e a função do modelo ideal nas artes não podem ser consideradas sem que se leve em conta seu componente fisiológico, como extensão do materialismo defendido pelo autor. No entanto, no trânsito da matéria sensível à articulação de ideias, outros fatores intervêm, consequentemente, torna-se insuficiente a explicação sensacionista.

A hipótese a ser defendida aqui é de que o modelo ideal vá além, não apenas do sensacionismo, mas também da leitura subjetivista segundo a qual as ideias sejam fruto de um processo cognitivo individual, estritamente interior. Para Diderot, o modelo de interpretação de um papel é concebido em ideia pelo comediante. Sua expressão corporal, sua declamação e a caracterização da personagem como um todo devem basear-se nesse ideal. Ambas as conotações da noção de ideal - um modelo que só exista em ideia e que seja o ideal a ser buscado - estão ligadas à possibilidade de a arte manter seu vínculo com a natureza. Isso quer dizer que a arte, embora seja um artifício, pode contribuir para preservar a tendência natural do homem à sociabilidade. 
No âmbito das instituições humanas, o sistema político constitucional, garantindo que todos sejam iguais perante a lei, vem corresponder à igualdade existente entre os membros da espécie humana. Desse modo, todas as demais convenções, dentre as quais o teatro, ganham significado ao postular esse ideal.

Assim, o modelo ideal não se origina da experiência individual. Tanto a ideia que orienta seu desempenho, quanto o ideal a ser perseguido pelo ator emanam do solo da política, mais especificamente, uma vertente da política ancorada no ideal iluminista de direitos iguais para todos, contrária aos privilégios das elites, de modo que na plateia nenhum espectador as admire, nem queira se identificar com elas. Além disso, não se admite que nenhum cidadão seja colocado em situação de marginalidade, de depauperamento ou alienação total de direitos. Ocorrendo em cena, em qualquer outra obra de arte ou na sociedade, será uma situação provisória a ser revertida ou vista como abjeta, de modo que ninguém considere natural permanecer nessa condição.

Segundo Diderot, a solução para o problema da elaboração de um modelo ideal que, embora seja um artifício, faça jus à condição de igualdade natural em que se encontram os membros da espécie humana, passa necessariamente pela teoria da linguagem. O modelo ideal tem como ponto de partida determinada disposição fisiológica, mas se engendra e se expressa por meio de técnicas e discursos elaborados por um grande número de pessoas, e não por um indivíduo, em estado de isolamento.

Ainda que as palavras e todo tipo de discurso não correspondam exatamente às ideias, Diderot os considera indispensáveis para que o pensamento entre em operação. O que se pretende demonstrar é que, dado o caráter convencional da linguagem, para que o pensamento se desenvolva plenamente deve ser ob- 
servada a equanimidade nas relações socioeconômicas. Diderot encontra assim na própria dinâmica do pensar a justificativa para sua opção política.

\section{$* * *$}

Diderot se refere ao modelo ideal pela primeira vez em 1751, no verbete Admiração:

Admiramos em geral aquilo que esteja acima de nossas forças ou para além do conhecimento que já temos. [...] Quanto mais uma criatura pensante vê longe no âmbito da natureza, tanto maior será seu discernimento, e ele se admira disso. De resto, é preciso ter cuidado com esse que é o primeiro movimento de nossa alma diante da presença de objetos, para que ninguém se entregue a ele sem o respaldo de algo conhecido, de modelos aos quais se possa relacionar o objeto presente. Os modelos devem ser de uma beleza universalmente aceita. Há espíritos que dificilmente se espantam, aqueles que a metafísica elevou acima do que já foi feito, que relacionam tudo o que veem, escutam etc., ao que seja possível, e que estabeleceram para si um modelo ideal abaixo do qual permanecem todas as criaturas e tudo o que já foi criado. (Diderot, 1751, p. 140-141)

Define-se aqui o projeto de distinguir a objetividade do conhecimento, para além da variabilidade dos dados da percepção sensorial. Na obra ulterior de Diderot, o modelo ideal se espraia da ciência para as artes, regendo o trabalho do poeta, do pintor, do escultor ou do ator. O ponto de vista do escultor estaria referido no próprio verbete Enciclopédia: 
Considerando-se que a perfeição absoluta de um plano universal não remediaria a fraqueza de nosso entendimento, apeguemo-nos ao que convém à nossa condição de homem e contentemo-nos em retornar a alguma noção bem geral. Quanto mais o ponto de vista de onde considerarmos os objetos for elevado, mais ele nos descobrirá em extensão e mais a ordem que seguiremos será grande e instrutiva. [...] Como estabelecer uma justa proporção entre as diferentes partes de um todo tão grande? Se esse todo fosse a obra de um homem só, a tarefa não seria fácil; o que é, pois, essa tarefa, quando o todo é obra de uma sociedade numerosa? (Id. 2011, p. 16-166).

Segundo Diderot, o modelo ideal assim estabelecido seria comparável a uma estátua colossal, como se toda a coletividade se incluísse aí. Do alto, o campo de visão é muito mais amplo do que aquele que se tem de baixo, do minúsculo ponto de vista do indivíduo, portanto o potencial de conhecimento também é mais abrangente.

O paralelo com a estatuária se repete nas Conversas sobre $\mathrm{O}$ filho natural, publicadas em 1757, bem como no Discurso sobre a poesia dramática:

Tomemos essa estátua e animemo-la. Concedamos a ela os órgãos mais perfeitos que o homem possa ter. Dotemo-la de todas as qualidades que um mortal pode possuir e nosso modelo ideal estará feito. [...] Pois eu teria o modelo ideal de toda verdade, de toda bondade e de toda beleza. Mas é impossível formar este 
modelo ideal, a menos que os deuses me concedam sua inteligência e me prometam a eternidade (Id. 2006, p. 129).

Descartadas a onisciência e a imortalidade, serão concebidos vários modelos ideais que deem régua e compasso ao movimento do pensar: o escultor lançará mão de sua arte para chegar ao modelo ideal, o pintor se remeterá à sua e assim por diante. Que o filósofo siga o mesmo caminho. Tudo que parecer bom e belo para este modelo, assim será. Tudo o que lhe parecer, falso, ruim e disforme, assim será. Eis o instrumento de suas decisões. (Ibid., p129-130). A noção de beleza resulta de um julgamento baseado em um parâmetro existente somente em ideia. O que se aproximar dessa ideia será considerado belo, o que se afastar, feio, desagradável.

É preciso, no entanto, saber como se concebe a ideia que servirá de ponto de ligação entre os diferentes conteúdos do pensamento.

Yvon Belaval tende a considerar o modelo ideal como resultado de um processo indutivo, funcionando como bastidor no entrelaçamento de impressões e ideias soltas, razão pela qual Diderot teria optado por um platonismo invertido: "não se parte de um mundo das Ideias que se degrade no mundo sensível; parte-se de um mundo sensível para ascender gradualmente a um mundo das ideias - sem maiúscula - que não são nem divinas nem imutáveis, mas conquistas do homem" (Belaval, 1950, p. 299).

Jacques Chouillet tem outra visão, notando que inferir uma conclusão a partir de múltiplas observações faria com que nossas ideias se submetessem a um determinismo orgânico, o que 
não condiz com a primazia atribuída ao juízo na abordagem de Diderot sobre nossas qualidades fisiológicas ${ }^{1}$. Seguindo essa linha, é preciso lembrar que em textos como Da interpretação da natureza, de 1753, nos quais Diderot descreve o método experimental em seu caminho da observação à hipótese, chega-se à conclusão de que a própria captação do fenômeno implica presença de espírito:

Uma vez que os sentidos eram a origem de todos os nossos conhecimentos, era muito importante saber até onde podíamos contar com o testemunho deles: acrescentamos aqui que o exame dos suplementos dos nossos sentidos ou instrumentos não é menos necessário [...] para o filósofo cuja ocupação diária é apoderar-se das diferenças mais insensíveis (Diderot, 1989, p. 73 e 79).

Esse exame dos suplementos dos nossos sentidos ou instrumentos equivale a uma instância de controle do próprio processo indutivo, responsável por ajuizar sua conformidade a padrões objetivos. Até mesmo a questão de gosto passa por esse crivo.

Diz-se, em literatura, nunca é preciso disputar gostos: se se entende que nunca é preciso discutir com um homem que seu gosto é tal, isto é uma puerilidade; se

${ }^{1}$ Cf. Chouillet, Jacques. La formation des idées esthétiques de Diderot. Paris: Armand Colin, 1973, pp. 462 e 479. Cf. ainda Dieckmann, Herbert. Diderot's conception of genius. In Journal of the History of Ideas. Vol. 2, $\mathrm{n}^{\mathrm{O}} 2$, abril de 1941, p. 176. 
se entende que não há nem bom nem mau gosto, isso é uma falsidade. O filósofo examinará severamente todos estes axiomas da sabedoria popular. (Ibid., p. 80)

São postulados como esses que permitem contestar a tese de que o drama burguês preceituado por Diderot seja realista, seja um retrato de época resultante de uma espécie de pesquisa sociológica, contrastando com o caráter fantasioso da tragédia neoclássica. Para Diderot, o poeta e o encenador não reproduzem em cena um fato histórico, assim como o ator não retrata uma pessoa, embora nem por isso sua obra deixe de fazer sentido. $\mathrm{O}$ que lhe confere significado é o modelo em que os artistas se baseiam para realizar suas obras, um padrão que se poderia denominar subjetivo, projetado sobre o mundo exterior, mas sediado internamente. As condições em que se encontram as personagens de $O$ pai de família, peça escrita por Diderot em 1758, não são de fato induzidas da experiência. Como consta do Discurso sobre a poesia dramática acrescido à publicação da peça, são as condições que modificam o modelo ideal de caracterização da personagem, e não o oposto.

Impugna-se assim o império dos sentidos sobre a razão, e a sensação deixa de assegurar a veracidade do raciocínio. Sem a contraprova da experiência, no entanto, a alternativa seria cada cabeça, uma sentença, e o relativismo grassaria. Estaríamos aqui regredindo à instabilidade dos estados de ânimo do artista, à impossibilidade de distinguir padrões objetivos de execução e fruição da obra de arte. Nesse caso, como pleiteia Diderot no Discurso sobre a poesia dramática, se faz sentir a necessidade 
de procurar uma medida, um módulo fora de mim (Op. Cit., p. 128).

O que transporta o homem para fora de si, no entanto, não se encontra aquém do pensamento, pois o ajuizamento consiste em remeter incessantemente os dados da percepção ao modelo concebido em ideia. É preciso notar que a ideia tomada como modelo, embora tenha função reguladora, não precede a operação do pensamento, em razão de sua relação de dependência para com o discurso, o que será discutido mais adiante.

Se, no cotejo com o modelo ideal, a sensibilidade se mantém em constante emulação com a razão, o artista sai de si, não ao se entregar às emoções, mas ao dominá-las. O si mesmo se define então pelo sentimento, em que se resumem os interesses particulares, as tendências individuais, a vida íntima, a configuração física de cada um, ao passo que estar fora de si reverte em algo mais elevado, numa espécie de autoconsciência cujo exemplo máximo é o desempenho da atriz Clairon, descrito no Paradoxo sobre o comediante: ela fez para si um modelo ao qual procurou de início conformar-se; sem dúvida, concebeu esse modelo da maneira mais elevada, mais grandiosa e mais perfeita que lhe foi possível; mas tal modelo que tomou da história, ou que sua imaginação criou como grande fantasma, não é ela ( $I d ., 2000$, p. $33)$.

A atividade do ator consiste então em discriminar o significado das palavras que declama, do gestual, de todos os aspectos plásticos e musicais da encenação, significado que corresponde a instâncias mentais. Seu saber está em discernir que tipo de movimentos corporais, palavras ou sons se referem a sentimentos, enquanto outra inflexão vocal ou expressão corporal terá correspondência com a razão. 
A mudança de registro permite que Diderot afirme, nas Conversas sobre $\mathrm{O}$ filho natural, praticamente o contrário do que viria a dizer no Paradoxo sobre o comediante:

Felizmente uma atriz de juízo limitado, de penetração comum, mas de grande sensibilidade capta sem dificuldade um estado de alma e encontra sem pensar a inflexão que convém a muitos sentimentos diferentes que se confundem, e que constituem essa situação que toda a sagacidade do filósofo não analisaria. (Id., 2008, p. 122)

No Paradoxo: quero que [o comediante] tenha muito discernimento; acho necessário que haja nesse homem um espectador frio e tranqüilo; exijo dele, por conseqüência, penetração e nenhuma sensibilidade, a arte de tudo imitar, ou, o que dá no mesmo, uma igual aptidão para toda espécie de caracteres e papéis." (Id., 2000, p. 32)

Entra em discussão o predomínio da sensibilidade ou do sanguefrio no temperamento do ator. Como o Paradoxo sobre o comediante tem como ponto central a questão das qualidades principais de um grande comediante (Ibid.), é importante salientar o termo utilizado por Diderot para designar ambos os polos: qualidades, não faculdades. Discrimina-se, na opção do uso da palavra qualidade, o monismo defendido por Diderot.

Porque a disposição fisiológica faz ressaltar uma qualidade ou outra, não se pode hipostasiar o orgânico em uma faculdade oculta, pensamento pensante, influxo de outra categoria substancial. No Sonho de d'Alembert, Diderot desenvolve a noção e 
explica como se reúnem todas as existências em uma só natureza, a matéria. Desse modo, resolve-se o problema da pretensa união entre duas substâncias heterogêneas, anulando ao mesmo tempo a necessidade de uma terceira que promova essa ligação.

Embora do ponto de vista ontológico Diderot não estabeleça uma distinção entre sensação e pensamento, do ponto de vista epistemológico a sensação se apresenta antes de ser discriminada pela razão. Assim, tanto menor será a coerência lógica da linguagem artística e a univocidade de seu significado, quanto mais próxima estiver do campo das sensações.

$\mathrm{O}$ artista consegue discriminar essa diferença, em primeiro lugar por tomar os outros e a si mesmo como objeto de observação, considerando a tudo e a todos de modo distanciado: os artistas são espectadores assíduos do que se passa em torno deles [...]. Apreendem tudo o que os impressiona (Ibid, p. 35).

O sujeito dessa observação não é um indivíduo tomado pela emoção, e nesse aspecto a experiência artística se subtrai ao psicologismo. Mas para Diderot nem o sujeito cognoscente se isenta desse exame. Além de o sentimento ser objeto de investigação e assim se diferenciar de emoções que não tenham passado por esse crivo, em algum momento o observador se eleva acima do entendimento e julga até mesmo a validade de suas demonstrações. Por ter sido a força propulsora, o sentir ocupa aqui uma posição proeminente, numa espécie de inteligibilidade própria do sensível, o que poderá ser ilustrado em seguida, na análise do quadro O filho punido, de Greuze. Esse exemplar da pintura de gênero que poderia, sem tanto anacronismo, ser denominado melodramático, pode adquirir relevância maior do que a própria arte monumental.

Embora o juízo implique distanciamento com relação a am- 
bas as faculdades, numa perspectiva consciente tanto da sensibilidade quanto da razão, o modelo ideal daí derivado continuaria a se restringir à esfera do isolamento subjetivo. Nesta interpretação da noção de modelo ideal, o próprio sujeito é o módulo a que se remete qualquer conteúdo do pensamento, incluídos os sentimentos, restando assim a necessidade de comprovar a objetividade de seu juízo. Não haveria nenhuma referência objetiva ao modelo ideal, nem probabilidade de transmitir essa ideia por intermédio de uma obra de arte.

Assim, autores como Jacques mostram a necessidade de problematizar a noção de modelo ideal entendida como produto de um processo indutivo. Ao mesmo tempo, apresentam uma alternativa subjetivista à interpretação fisicalista do tema. No entanto, em suas proposituras não se chega a questionar a possibilidade de conceber tal modelo com base em ideias que tenham brotado e se confinem ao âmbito individual.

Neste artigo tenta-se resolver o problema do solipsismo, pelo viés da teoria da linguagem exposta por Diderot. Defende-se, portanto, que a efetividade das relações intersubjetivas seja o módulo ao qual se remeta a experiência de cada indivíduo, o que não entra em contradição com a afirmação de que seja acessível apenas em termos de pensamento, idealmente.

Não se pode restringir a discussão ao plano gnosiológico ou epistemológico - que, para Diderot, são correlatos -, porque, segundo o filósofo, outro fator antecede o exercício da razão, da sensibilidade, bem como a intervenção do juízo: para que tais qualidades se exerçam, é preciso que o homem disponha previamente de um discurso que, por sua vez, deriva de uma convenção coletiva correspondente a uma espécie de pacto político. É esse o fundamento objetivo, o módulo que unifica nossas próprias 
faculdades, ou melhor, qualidades.

Ernst Cassirer afirma que desde o século XVII a arte vinha buscando o máximo de objetividade possível, ainda que fosse expressão de um sujeito. "Pois uma coisa é o impulso que suscita o processo criador [...], e outra coisa é a obra que é o fruto desse impulso. Uma obra digna desse nome, criatura autônoma possuindo verdade e perfeição objetiva, deve despojar-se, em sua pura essência e em sua consistência, das forças subjetivas que eram indispensáveis à sua gênese." (Cassirer, 1992, p. 379)2

$\mathrm{O}$ ator de fato encarna essa desindividuação, objetivando seu pensamento, como se fosse o pensamento de outra pessoa ${ }^{3}$. Pensar como outra pessoa quer dizer, no caso do comediante, colocar-se em situação de diálogo para assumir um papel predeterminado por preceptivas poéticas, segundo a cláusula dos estados das personagens dramáticas. Esse discurso também se articula em gesto e declamação, cenografia, soluções arquitetônicas referentes à sala de espetáculos, ao local de apresentação.

Razão pela qual, dentre os artistas, o ator é o único a ter a possibilidade de adaptar constantemente seu trabalho à mudança de público. No caso do teatro, a convenção elaborada desde os gregos é preservada - a tragédia, a comédia -, embora receba outro tratamento, a fim de suscitar pensamentos, ideias e sentimentos nos mais diferentes tipos de público a que o ator

${ }^{2}$ Cf. Belaval, Yvon., 1950, p. 262, onde o autor propõe uma mudança de perspectiva que parece corresponder à diferenciação notada acima: na gênese ou na fase de construção da personagem, o ator aparece como sujeito da história a ser contada e para tanto libera sua sensibilidade; passado esse momento, executará seu papel com frieza, tornando-se uma obra de arte produzida por si mesmo.

3 Cf. Lewinter, Roger., 1976, p. 22: O procedimento favorito de Diderot: objetivar seu pensamento, emprestando-o a outrem - Saunderson, d'Alembert, Rameau. 
se dirija.

Diderot demonstra que o bom ator se notabiliza pelo julgamento que faz das condições de seu público e de suas personagens, de modo a aplicar adequadamente seus conhecimentos sobre a teoria dos gêneros literários, sobre técnicas de representação, sobre a declamação como um dos ramos da música, sobre a cena como um ramo das artes plásticas e da arquitetura.

Sendo sinais sensíveis de algo cujo significado está para além deles, todos os aspectos que envolvem a composição e a encenação de uma peça teatral têm em comum o fato de que seu significado seja fruto de um acordo: convenciona-se que signifiquem determinada ideia, pensamento ou sentimento, como Diderot afirma no Paradoxo sobre o comediante. No entanto, o caráter convencional da linguagem não leva Diderot a defender o relativismo ou a arbitrariedade semântica. O processo mediante o qual se estabelecem significados para determinados sons, movimentos corporais, disposição de objetos ou sinais marcados em um papel obedece a princípios objetivos, a fim de que possam ser comunicados e compreendidos.

O que permite a Diderot enfrentar esse paradoxo é justamente o caráter convencional de toda linguagem, em que se incluem as artes. Se os nomes se referem a ideias e não às coisas mesmas, "as palavras não são e não podem ser senão signos aproximados de um pensamento, um sentimento, uma ideia"(Diderot, 2000, p. 31). Ou seja, as palavras também não coincidem com as ideias que evocam. A linguagem aparece como substituto externo de pensamentos e sentimentos internos. Assim, toda linguagem é de instituição. A referência ao real se dá por uma suposição tácita que determina a adequação, no espírito, das ideias a seus enunciados verbais. O modelo ideal não corresponde a um ob- 
jeto nem imita algo que subsista na natureza, mas se refere ao modo como se processam pensamentos, ideias e sentimentos.

Ainda assim não haveria garantias de que a ideia do falante se tornasse uma ideia do ouvinte. O significado das palavras seria algo unilateral, tendo a ver exclusivamente com o falante e suas ideias privadas. Para evitar a alternativa individualista, Diderot propõe o estabelecimento de um critério objetivo de gosto e de beleza, dividido em três frentes: 1) nas qualidades que permitem ao homem deter algum conhecimento, 2) no caráter convencional da linguagem, 3) na sociabilidade característica da natureza humana.

Como se disse anteriormente, a sensação se apresenta ao pensamento antes de ser discriminada pela razão, mas o emaranhado de sensações deixa de sê-lo ao se conformar ao discurso. Por esse motivo, para que seja superada a indeterminação sensorial e para que as ideias surjam, é preciso dispor de um discurso elaborado, em que se inclui a linguagem poética.

Nas Conversas sobre O filho natural como no Discurso sobre a poesia dramática, Diderot se detém sobre os gêneros literários, com base na Poética aristotélica e na Arte poética, de Horácio. Na primeira das poéticas, são definidos os limites entre os gêneros literários. Na segunda, levanta-se a possibilidade de efetuar um cruzamento entre epopeia e drama, por um lado e, no interior deste gênero, entre tragédia e comédia.

Assim, como consta do Paradoxo sobre o comediante, para que a linguagem teatral adquira significado, não é suficiente colocar no palco a interioridade do comediante, seus segredos, sua vida sentimental e suas memórias, em primeiro lugar porque se trata de uma vivência pessoal, que ninguém, além do ator, compreenderia inteiramente. O teatro não é um gênero adequado 
para falar apenas do mundo interior, tem abrangência muitíssimo mais vasta em decorrência de uma instrução normativa que consta da "fórmula dada pelo velho Ésquilo: é um protocolo que data de três mil anos" (Ibid, p. 39). Chancelado desde então por gerações e gerações, tanto o público de teatro quanto o artista têm conhecimento prévio do que se espera desse espetáculo: o teatro tem um alcance maior, relativamente à poesia lírica; existe uma elocução adequada a cada gênero; certo tipo de assunto condiz com a forma da tragédia e outro com a forma da comédia etc. etc.

Os termos com que o artista lida são, portanto, predeterminados, assim como a estrutura de uma língua formada preexiste aos indivíduos que a pratiquem. No entanto, as relações que se estabelecem entre esses termos são imprevisíveis, e de seu entrecruzamento podem mesmo surgir novas formas, tais como a tragédia doméstica e a comédia séria, preceituadas por Diderot.

Por uma questão de decoro poético, o teatro não se limita à expressão da vida íntima, mas também porque, segundo Diderot, não há possibilidade de ninguém pensar individualmente sem o emprego de uma linguagem sancionada ou convencionada por um grupo de pessoas, durante uma passagem de tempo que supera a existência de cada falante da língua.

O teatro é um protocolo internacional, reconhecido por um sem número de pessoas desde a antiguidade, no entanto sua referência última são instâncias mentais, e não a Grécia antiga ou o mundo contemporâneo. Não há um modelo concreto que possa ser reproduzido em cena pelo dramaturgo ou pelo ator. Pode-se dizer que, para Diderot, todos os aspectos da encenação teatral, dentre os quais as palavras, não são e não podem ser senão signos aproximados de um pensamento, um sentimento, 
uma ideia" (Ibid., p. 31).

Embora aqui as teorias de Diderot estejam próximas de certa vertente da teoria da linguagem que percebe um hiato intransponível entre as ideias e os sinais sensíveis responsáveis por externalizá-las, ao mesmo tempo ele discorda de sua contrapartida epistemológica, segundo a qual o significado das palavras emana de uma experiência privada, sendo, portanto, intransmissível.

Se Diderot considerasse aleatório o emprego de determinado som, palavra ou notação visual para designar diferentes ideias, sentimentos e pensamentos, não haveria possibilidade de comunicação efetiva entre um indivíduo e outro. O verdadeiro significado das palavras, gestos, da linguagem plástica e escrita e até mesmo da música ficaria restrito à mente do emissor, do poeta, do artista. Um filósofo do século XX notou que, pelo fato de ter seu significado estabelecido unilateralmente, sem a participação de interlocutores, tratar-se-ia de uma linguagem privada. Além disso, como os nomes não encerram nenhuma essência, a atribuição de significado se tornaria arbitrária.

Diderot admite que toda linguagem seja uma convenção, mas ao mesmo tempo subscreve teorias que na França da primeira metade do século XVIII colocaram em xeque a noção de que o pensamento se articulasse independentemente da linguagem ${ }^{4}$. Toda atribuição de significado seria arbitrária se, em primeiro lugar, as palavras pudessem ou não existir, sem prejuízo de nossas atividades intelectuais. Porque a linguagem não corresponderia de modo algum ao pensamento, não precisaríamos absolutamente da linguagem para pensar, apenas para exteriorizar pensamentos.

${ }^{4}$ Cf. Robinet, 1978, pp. 181 e ss. 
Para que Diderot resolvesse o problema, em primeiro lugar foi necessário eliminar qualquer traço da existência de faculdades ocultas. No entanto, a fim de que o pensamento entre em atividade, em não havendo pensamento pensante, o homem deve previamente dispor de um discurso. Disso se conclui que o estabelecimento das línguas seja anterior à formação das ideias. "São os signos que engendram as ideias e não vice-versa", afirma Chouillet (1973, p. 159).

Porque um ser privado de sinais seria privado de inteligência, a ligação entre ideias só pode se dar por meio da linguagem, sendo este o único princípio ativo do conhecimento. A conclusão é que o raciocinar se inicia com o estabelecimento das línguas. Sem a contribuição dos outros, nenhum indivíduo conseguiria pensar, pois é em conjunto que os homens estabelecem acordos, convenções.

Diderot defende, portanto, que a linguagem seja condição sine qua non para que o pensamento se desenvolva. Antes de tudo é necessário que se estabeleça um acordo sobre o significado dos sinais sensíveis, a fim de que funcionem, exteriormente, como sucedâneos das ideias. Esse acordo é fruto da convivência entre as pessoas, bem como do posicionamento individual frente à coletividade. Diderot conclui que, no estado de isolamento, o homem ainda não se define como sujeito pensante, visto que, sem nenhum contato interpessoal que defina o significado desses sinais, o pensamento permanece inoperante.

Na seguinte passagem da Carta sobre os cegos, Diderot expõe a necessidade de conciliar ambas as teses:

Nossos sentidos nos reconduzem a signos mais análogos à extensão de nosso espírito e à conformação de 
nossos órgãos. Fizemos mesmo as coisas de maneira que esses signos pudessem ser comuns entre nós, e que servissem, por assim dizer, de entreposto ao comércio mútuo de nossas ideias. Instituímos alguns para os olhos, são os caracteres; para o ouvido, são os sons articulados; mas não possuímos nenhum deles para o tato, embora haja maneira peculiar de falar a esse sentido, e de obter dele respostas. À falta desta língua, a comunicação fica inteiramente rompida entre nós e os que nascem surdos, cegos e mudos. Eles crescem; mas permanecem em estado de imbecilidade. Talvez adquirissem ideias, se nos fizéssemos entender por eles desde a infância, de maneira fixa, determinada, constante e uniforme, em suma, se traçássemos sobre a mão deles os mesmos caracteres que traçamos sobre o papel, e se a mesma significação lhes permanecesse invariavelmente vinculada. [...] Os conhecimentos têm três portas para entrar em nossa alma, e nós mantemos uma trancada por falta de sinais. Se se houvessem negligenciado as duas outras, estaríamos reduzidos à condição dos animais. (Diderot, 1984, p. 11)

Nas passagens acima sublinhadas, Diderot deixa claro que o pensamento não se mobiliza sem intermediação da linguagem. Daí a importância da atividade do comediante no campo estético, moral e civil. O ator permite que se comuniquem ideias surgidas muito antes ou muito além das convenções locais, ideias que surgiram e se expressam, por exemplo, por intermédio do protocolo trágico ou cômico convencionado pela pólis grega. 
Não ocorre cisão entre o eu e o mundo porque o eu sequer se constitui sem a participação do mundo, sem que se convencione o significado dos sinais sensíveis. Do mesmo modo, segundo Diderot, o estado de natureza não se dissolve no estado civil. Como observa Maria das Graças de Souza, pensamento, linguagem e sociabilidade são elementos da natureza humana. O estado de natureza, não é, portanto, uma situação hipotética (Souza, 2002, p. 123).

Assim, a linguagem só contraria o pendor natural quando estimula o individualismo, provocando a discórdia geral e consequentemente ameaçando a própria vida. Pois a livre associação tem como finalidade preservar a vida, enfrentar com maior facilidade a luta pela sobrevivência e pelo bem-estar. [...] O pacto não significa uma ruptura com um estado de natureza, mas decorre da própria natureza. (Ibid., p. 126)

A linguagem é uma convenção - toda linguagem sendo fruto de um acordo sobre o significado dos sinais sensíveis -, portanto sua gênese só pode ser social. Assim, a origem das línguas, bem como o aparecimento de determinadas formas artísticas, estão atrelados a regimes políticos. Isso implica, pela subordinação do pensamento ao discurso defendida por Diderot, que tampouco a lógica do pensar possa ser definida como isenta ou neutra, mas, sim, comprometida com uma variegada gama de opções políticas.

A autonomia do artista não está em se desvencilhar dos biombos da linguagem e promover a transparência total. Não há transparência de sentimentos, pensamentos e ideias, visto que nossas ideias dependem da linguagem para que sejam concebidas, surgindo de uma experiência coletiva e não do âmago do indivíduo. 
O modelo ideal funciona justamente como corretivo, como unidade de medida que impeça o abuso individual, portanto arbitrário, no incremento de ideias. "'A natureza humana é portanto boa?' Sim, meu amigo, é muito boa. (...) Não se deve acusar a natureza humana, mas as miseráveis convenções que a pervertem. [...] Num povo escravo, tudo se degrada (Diderot, 2005, p. 45 e 107), afirma Diderot no Discurso sobre a poesia dramática. No caso em que as convenções se tornem prejudiciais aos indivíduos e ao corpo social como um todo, tanto a razão quanto a sensibilidade podem intervir, pelo bem da espécie humana.

Três anos antes, no verbete Direito natural, da Enciclopédia, Diderot havia dito que o bem comum somente se contempla de um ponto de vista mais elevado que os interesses particulares, portanto a justiça está na preeminência do geral sobre o particular:

Se privarmos o indivíduo do direito de decidir sobre a natureza do justo e do injusto, a quem remeter esta grande questão? A quem? Ao gênero humano: somente a ele cabe decidi-la, pois o bem de todos é sua única paixão. As vontades particulares são suspeitas; podem ser boas ou más, mas a vontade geral é sempre boa: jamais se enganou, jamais se enganará. (Id., 1995, p. 46)

O modelo ideal emana de um constructo coletivo ${ }^{5}$ que lhe

\footnotetext{
${ }^{5}$ Cf. Beck, 1994, p. 537: Diderot não parece restringir essa atividade ao indivíduo, mesmo que seja um gênio, mas lhe confere uma dimensão coletiva, na medida em que a busca se efetua no campo de determinada cultura.
} 
confere objetividade frente às tendências individualizantes, mas é preciso ainda coibir a propensão a universalizar padrões locais. Daí Diderot defender que nossas ideias sejam fruto de uma longa elaboração no tempo e no espaço. Do mesmo modo que a elaboração de uma ideia, ligada à formação de uma língua, demanda um tempo bem maior que a duração da vida de uma pessoa, a criação de um papel não se enquadra apenas no espaço em que um indivíduo circula, implicando um leque muito mais amplo de relações.

O módulo que orienta todo o movimento do pensar, mas que ao mesmo tempo se destaca de instâncias psicológicas e pode, assim, ser aplicado universalmente, tomado como padrão objetivo, é a preservação da espécie humana. A sociabilidade decorrente da inclinação natural à preservação da espécie - subordinando qualquer interesse privado -, não se confunde entretanto com um estado de natureza ahistórico, na medida em que esse ideal somente se formula mediante o emprego dos mais variados tipos de linguagens. Linguagens, como se tem dito, elaboradas por uma convenção que vincula sinais sensíveis a significados de outra ordem.

Ao comentar que a personificação da França em um mausoléu realizado pelo escultor Pigalle não possa ser definido como imitação, e, sim, como uma amplificação operada pelo artista, Diderot se justifica apelando à desproporcionalidade entre o individual e o coletivo: [Pigalle] trabalhava então no seu monumento ao Marechal [da Saxônia], e uma belíssima cortesã servia-lhe de modelo para a figura da França. Mas como acreditais vós que ela me pareceu entre as figuras colossais que a cercavam? Pobre, pequena, mesquinha, uma espécie de rã; estava esmagada por elas (Diderot, 200, p. 74). 
Como se vê no detalhe, a França transtornada, envolta em panejamento flor-de-lis, tenta impedir que o marechal desça para a tumba, onde o espectro da morte o aguarda. À esquerda, estandartes depostos e animais abatidos representam a coalisão inimiga, Áustria (águia), Holanda (leão) e Inglaterra (leopardo), derrotada pelo marechal de França em 1745. Hércules, desolado, remete à Casa Farnèse. Em contraponto, à direita, bandeiras francesas estão hasteadas, e o gênio da guerra - ou o próprio amor - se encontra em prantos na despedida do marechal ${ }^{6}$.

É bem provável que o contraste notado por Diderot já não faça sentido e que não haja diferença entre uma cortesã e a corte francesa. A França teria se prostituído ao transformar os valores individuais em ética, fazendo com que o amor-próprio se tornasse regra geral. Em política, seria o mesmo que atentar contra a lei maior, a constituição. Diderot declara-se defensor do constitucionalismo já em 1751, no verbete "Autoridade política", do primeiro volume da Enciclopédia, ao declarar que "o poder verdadeiro e legítimo, pois, tem necessariamente limites. [...] O príncipe recebe dos seus próprios súditos a autoridade que tem sobre eles, e esta autoridade é limitada por leis da natureza e do Estado." (Diderot, 2006,p. 39). Como o sistema constitucionalista determina que todos, governantes e súditos, se subordinem às leis mas não se sujeitem a nenhum homem, assim, a liberdade no estado civil está em cumprir a lei. Aqui a própria obediência é gloriosa, ao passo que, nos casos em que o governante ou facções poderosas se coloquem acima das leis, as instituições passam a ser odiosas e a obediência, aviltante.

Uma grande máquina acadêmica como o mausoléu do Mare-

${ }^{6}$ Cf. Idem. Lettre à Jean-Baptiste Pigalle (2/10/1756) In Oeuvres. Ed. L. Versini. Tomo V. Paris: Robert Laffont, 1997, pp. 60-62. 
chal da Saxônia perde então o significado, já não corresponde a seu suporte material. As dimensões do mausoléu, que alcança mais de 10 metros, são proporcionais ao tratamento alegórico que se aplica a assuntos elevados como a segurança de um povo, a resistência ao inimigo e a vitória na guerra. Mas esse monumento fúnebre não pode mais designar o que se espera dele, em lugar disso se ouve um coaxar insignificante vindo de baixo.

Se a objetividade, a abrangência de um ponto de vista é proporcional à sua altura, a verdadeira arte contempla, de preferência, toda a humanidade. Diante disso, é necessário que o artista tome distância de temas menores como os retratos da vida privada que definem a pintura de gênero. No teatro, tentando atuar com sentimento, atores e atrizes apequenam-se, agem de acordo com interesses pessoais, apegam-se a um pequeno círculo de amizades, em prejuízo do bem comum.

A boa convenção garante nossa autonomia, portanto não concorre para que as pessoas se sujeitem à dominação; nesse sentido a natureza humana é boa e, não, fator de relações conflituosas. As miseráveis convenções, estas, sim, antinaturais, são aquelas que conduzem o pensamento e o sentimento a ratificar desigualdades.

Para que o comediante se veja como outro, não necessariamente deverá colocar-se de uma perspectiva elevada; também nos momentos em que ele se volte para a intimidade há o emprego deliberado de um artifício. Aqui o desempenho comovente não parte de uma vivência pessoal, mas da utilização de recursos distintos daqueles que se empregam em obras monumentais. Ainda que os grandes temas da arte, segundo Diderot, tenham passado a expressar ganância e baixeza na condução dos negócios públicos, e assim deixem de atrair a admiração do receptor, 
é possível tocar o coração mediante uma mudança de registro em direção à tópica da humildade.

Em cenas como a que Greuze representa no quadro $O$ filho punido, é da vida privada, do sentimento nutrido no interior de um lar modesto que se vão alastrar sentimentos humanitários. Sabe-se, pelo quadro que completa o díptico, que o filho ingrato havia abandonado a família para se aventurar na guerra, e agora retorna com perna e braço feridos, alquebrado e usando uma bengala para caminhar. Como sua ausência fez diferença no sustento da família humilde, a situação piorou bastante: o pai acaba de falecer; sua mãe, irmãs e irmãos menores entram em desespero, é tarde demais para o arrependimento visível no gesto do recém-chegado.

Aqui o artista não nos transporta às alturas do mausoléu do marechal da Saxônia, porque já não se trata de conduzir o particular à esfera pública, pelo distanciamento. No quadro de Greuze, atenua-se a monumentalidade que integra o indivíduo à sociedade, na medida em que também o apequenar-se favorece a agregação, fortalece a coesão das partes, para que o todo não se desfaça. A identificação com os sofredores e os humildes vai de par com a rejeição àqueles que tenham um papel de destaque, àqueles que estejam em posição de superioridade e se valham disso para beneficiar-se.

Em texto de 1774 sobre a elaboração das leis no império russo, as Observações sobre o Nakaz, Diderot diz ser

Raro que um povo se submeta sinceramente a leis que lhe sejam impostas; mas vai amá-las, respeitá-las, obedecê-las e defendê-las [...], se ele mesmo for seu autor. Não se trata mais da vontade arbitrária de um 
só, é a vontade de numerosos homens, após terem consultado uns aos outros sobre sua felicidade e sua segurança; existem em vão, se não se impõem igualmente a todos; existem em vão, se houver um único membro da sociedade que as infrinja impunemente. (Id., 1995, p. 507)

Na passagem acima, percebe-se que o constitucionalismo defendido por Diderot implica 1) que a lei esteja acima de todos - impondo-se a quaisquer estados - 2) e que todos sejam iguais perante a lei - governantes e súditos devem receber o mesmo tratamento, caso infrinjam a lei. O primeiro aspecto está contemplado nos estilos majestáticos, a exemplo do referido mausoléu, bem como, em termos de gênero literário, a épica e a tragédia. O segundo aspecto, além de contemplar a pintura de gênero, abarca a tragédia doméstica e a comédia séria, preceituadas por Diderot.

Embora a temática da piedade também se configure como deformação, como miniaturização, portanto tão fictícia quanto a amplificação realizada por Pigalle no mausoléu, nesses casos também a emoção poderá se impor como padrão objetivo de beleza e bom gosto.

É que ser sensível é uma coisa, e sentir é outra. A primeira é uma questão de alma e a outra, uma questão de julgamento. É que sentimos com intensidade o que não saberíamos expressar [...]; é que abranger toda a extensão de um papel [...] é obra de uma cabeça fria, de um profundo julgamento, de um gosto refinado, de 
um estudo penoso, de uma longa experiência ( $I d, 2000$, p. 74).

Empregar determinada técnica é uma decisão que acarreta consequências diversas, na medida em que o artista propõe ao público um modelo de comportamento na vida privada, de atuação na vida pública, bem como um padrão cognitivo. A obra de arte torna-se um modelo ideal quando puder agradar, ao mesmo tempo em que se mostre desinteressada. Desinteressada porque os interesses particulares são deixados de lado para evitar dissensões, as quais chegam a ameaçar a própria vida. Ao mesmo tempo, a arte não deve se limitar à vivência íntima do prazer sensorial, pois sua função é promover uma convivência harmoniosa, requisito para a preservação da espécie. Esta tendência natural é compatível com a finalidade última de toda instituição humana: fortalecer os laços entre as pessoas, o que não se faz sem que, no campo da economia e da política, a igualdade deixe de ser uma questão de costume, para ser garantida por lei.

Pode-se dizer que no campo da teoria literária seja consensual a alegação de que o romantismo em literatura pregue a igualdade entre os homens. Em consequência disso, multiplicam-se no campo da ficção os conflitos causados por impedimentos contra relações amorosas mantidas entre nobres e burgueses, ou entre ricos e pobres, tendo em geral como desenlace os casamentos interclasses ${ }^{7}$.

Diderot não contava, entretanto, que a introversão se tornasse definitiva e que toda arte se restringisse desde então a um único tema, a vida privada em seus diversos matizes - o drama em família; a separação radical entre indivíduo e sociedade, entre o

7 Cf. Lukács, 2010, pp. 145 ss. 
eu e o mundo; segredos interiores, conflitos psicológicos. Certamente a guinada de todas as artes em direção ao drama burguês, impedindo que o pensamento extrapolasse a vida interior ou, se muito, as quatro paredes de um lar, favoreceu o interesse dos déspotas de que poucos se imiscuíssem na vida pública.

\section{Referências bibliográficas}

BECQ, A. Génèse de l'esthétique française moderne 1680-1814. Paris: Albin Michel, 1994.

BELAVAL, Y. L'esthétique sans paradoxe de Diderot. Paris: Gallimard, 1950.

CASSIRER, E. "Os problemas fundamentais da estética". In A filosofia do Iluminismo. Trad. de A. Cabral. Campinas: UNICAMP, 1992.

CHOUILLET, J. La formation des idées esthétiques de Diderot. Paris: Armand Colin, 1973.

. "Enciclopédia". In Guinsburg, J. e Romano, R. Diderot-

Obras VI (3). Trad. de N. Cunha e J. Guinsburg. São Paulo: Perspectiva, 2011.

de Mattos. São Paulo: Cosac Naify, 2005.

- Da interpretação da natureza. Trad. de M. C. Santos. São Paulo: Iluminuras, 1989.

- Paradoxo sobre o comediante. Tradução de J. Guinsburg. In Guinsburg, Jacó. Diderot - Obras II. São Paulo: Perspectiva, 2008.

Diderot - Obras V. O filho natural. São Paulo: Perspectiva, 
2008.

Guinsburg. Os Pensadores. São Paulo: Abril, 1984.

. "Droit naturel", § 6. In Oeuvres. Ed. L. Versini. Tomo III. Paris: Robert Laffont, 1995.

. "Lettre à Jean-Baptiste Pigalle (2/10/1756)". In Oeuvres.

Ed. L. Versini. Tomo V. Paris: Robert Laffont, 1997.

"Autoridade política". In Verbetes políticos da Enciclopédia. Tradução de M.G. de Souza. São Paulo: Discurso, 2006.

- Observations sur le Nakaz. In Oeuvres. Ed. L. Versini. Tomo III. Paris: Robert Laffont, 1995.

DIECKMANN, H. "Diderot's conception of genius". In Journal of the History of Ideas. Vol. 2, n ${ }^{\circ}$ 2, abril de 1941.

LEWINTER, R. Diderot ou les mots de l'absence. Paris: Champ Libre, 1976.

LUKÁCS, G. "Posfácio". In: Goethe, J. W., Os anos de aprendizado de Wilhelm Meister. Tradução de N. Simone Neto. São Paulo: Editora 34, 2006.

ROBINET, A. Le langage à l'âge classique. Paris: Klincksieck, 1978.

SOUZA, M. G. Natureza e Ilustração: sobre o materialismo de Diderot. São Paulo: , 2002.

STRAUSS, L. Direito natural e história. Trad. de M. Morgado. Lisboa: Edições 70, 2009.

WATT, I. A ascensão do romance. Tradução de H. Feist. São Paulo: Companhia das Letras, 2010. 